\title{
O PROTAGONISMO DAS MULHERES NAS INICIATIVAS DE ECONOMIA POPULAR E SOLIDÁRIA COMO ALTERNATIVA DE GERAÇÃO DE RENDA: SERÁ ESSA A RESPOSTA PARA A IGUALDADE DE GÊNERO?
}

\author{
Juliana de Freitas Silva ${ }^{1}$; José Raimundo Oliveira Lima² \\ 1 Bolsista de Iniciação Científica PIBIC/CNPq, Graduanda em Ciências Econômicas pela Universidade Estadual de Feira de \\ Santana: july.afrox@hotmail.com. \\ 2 Orientador, Departamento de Ciências Sociais Aplicadas da Universidade Estadual de Feira de Santana, Coordenador do \\ Programa Incubadora de Iniciativas de Economia Popular Solidária da Universidade Estadual de Feira de Santana: \\ zeraimundo@uefs.br.
}

PALAVRAS CHAVE: Economia Popular e Solidária; Mulher e Mercado de Trabalho; Desenvolvimento Local.

\section{INTRODUÇÃO}

Estre trabalho é o resultado do relatório final de pesquisa apresentado ao $\mathrm{CNPq}$, com o objetivo de responder a seguinte pergunta: $\mathrm{O}$ que torna as iniciativas de economia popular e solidária favorável para que a maioria dos membros seja composta por mulheres? Para tanto utilizou-se de referência que possibilitasse uma reflexão sobre economia popular e solidária, mulher e mercado de trabalho numa abordagem de pesquisa participativa ao qual foi realizado estudo de caso como também a aplicação de um questionário afim de analisar a participação das mulheres trabalhadoras nas iniciativas de economia popular e solidária como alternativa de geração de renda e autovalorização diante do mercado de trabalho.

A teoria tenta explicar as desigualdades existentes no mercado de trabalho e a economia popular e solidária como "outra economia" se propõe a diferenciar-se da economia convencional inerente ao sistema capitalista por este apresentar aspectos que valoriza o capital em detrimento do trabalho, os quais são denominados de fatores de produção, o que corrobora com a teoria neoclássica que afirma por meio dos modelos econômicos que para uma empresa obter um ponto de maximização dos lucros é necessário que haja substituição do trabalho por capital numa relação $\mathrm{Y}=\mathrm{K} \quad \alpha \quad \mathrm{L}^{1-\alpha}$

Dessa forma a teoria neoclássica estabelece a função de produção para valorizar o capital com a desvalorização do trabalho e como consequência gera o desemprego.

É nesse contexto que emerge a economia popular como uma alternativa ao desemprego, onde os trabalhadores excluídos do processo de acumulação de capital decidem produzir ou comercializar bens para geração de trabalho e renda sem necessariamente realizar uma organização de grupo.

Tentando obter o mesmo objetivo de geração de emprego e renda a economia popular solidária propõe uma organização desses sujeitos de maneira a tornar o movimento da economia popular em uma economia política dos setores populares a fim de organizar os grupos isolados numa perspectiva de redes. Essa aproximação pode ser obtida por meio das incubadoras que se propõe a desenvolver um trabalho politico pedagógico que possibilita as iniciativas a se organizarem enquanto grupo produtivo autogestionário.

A economia popular e solidária como economia política dos setores populares sugere uma aproximação das incubadoras com os grupos para que juntos possam criar alternativas de geração de renda de modo que o trabalho seja o fator protagonista. Nesse sentido, existe um ponto de equilibrio entre o capital e o trabalho? Existe mercado para a economia popular e solidária da forma como a mesma se propõe ser outra economia? O que caracteriza a economia popular e solidária como outra economia?

Outra indagação pertinente a ser feita em relação à economia popular e solidária enquanto economia política dos setores populares é sobre a abordagem que é feita em relação à participação das mulheres uma vez que as mesmas são em números a maioria dos membros 
participantes das iniciativas, pelos menos as iniciativas que a incubadora acompanha. Um questionamento a ser feito a respeito desses números é por que essas mulheres escolhem por essa forma de trabalho autogestionário e não pelo tradicional do mundo do trabalho. Pensando nessa pergunta fez-se necessário o estudo de caso nos grupos informais Sabores do Quilombo e Companheiras de Mãos Solidárias (COOPERMASOL) que ocupam o espaço da cantina dos módulos I e VII - respectivamente da Universidade Estadual de Feira de Santana.

Neste contexto o objetivo desse trabalho é discutir a opção das mulheres que trabalham nos projetos cantina solidárias I e III pela forma de trabalho autogestionário e não pela forma do tradicional do mundo do trabalho.

Com efeito, ambos os grupos foram selecionados pela incubadora para fazer parte do Projeto Cantina Solidária I e III ${ }^{1}$ os dois grupos apresentam características comum no que se refere à composição orgânica, o primeiro grupo COOPERMASOL possui a composição majoritário por mulheres enquanto que o grupo Sabores do Quilombo possui um homem como integrante do grupo, também majoritariamente mulheres.

Nesta esteira, neste artigo faremos uma caracterização sobre a economia popular e solidária e também sobre a economia convencional, a partir dos elementos que se contrapõe com ênfase nos aspectos que circundam o trabalho, bem como o trabalho das mulheres e suas escolhas por trabalhar em eu uma economia em detrimento da outra.

\section{METODOLOGIA}

Ao realizar um estudo de caso o pesquisador se depara com a realidade e tenta explica-la pela teoria o que às vezes não acontece de maneira rápida e coerente o que a torna fascinante, pois proporciona uma experiência de aprendizagem entre o saber cientifico e o saber popular, sendo assim a pesquisa-ação adotada como procedimento metodológico responde em grande parte ao que se propõe pelas incubadoras universitárias, haja vista que as mesmas têm como fundamento a educação política pedagógica dos sujeitos envolvidos nas iniciativas de economia popular e solidária por meio do processo de incubação que permite essa interação ente a universidade e a comunidade configurando a extensão universitária para além para além dos muros acadêmico.

Nossa posição consiste em dizer que toda pesquisa-ação é de tipo participativo: a participação das pessoas implicadas nos problemas investigados é absolutamente necessária. No entanto, tudo o que é chamado pesquisa participante não é pesquisa-ação. Isso porque pesquisa participante é, em alguns casos, um tipo de pesquisa baseado numa metodologia de observação participante na qual os pesquisadores estabelecem relações comunicativas com pessoas ou grupos da situação investigada com o intuito de serem melhor aceitos. Nesse caso, a participação é sobretudo participação dos pesquisadores e consiste em aparente identificação com os valores e os comportamentos que são necessários para a sua aceitação pelo grupo considerado (THIOLLENT, 1947, p.09).

Dessa forma a pesquisa participante pode acontecer sem necessariamente existir uma ação, porém o contrário não acontece já que para propor uma ação que possibilite em transformação da realidade é imperativo que haja participação do pesquisador com a comunidade.

Para muitos de nós, a realidade concreta de uma certa área se reduz a um conjunto de dados matérias ou de fatos cuja existência ou não, de

\footnotetext{
${ }^{1}$ Projeto de incubação desenvolvido pelo Programa Incubadora de Iniciativa de Economia Popular e Solidária da Universidade Estadual de Feira de Santana - PIEPS-UEFS com o objetivo geral de incubar grupos de iniciativas de economia popular e solidária utilizando o espaço da Cantina da UEFS com caráter político e pedagógico.
} 
nosso ponto de vista, importa constatar. Para mim, a realidade concreta é algo mais que fatos ou dados tomados mais ou menos em si mesmos. Ela é todos esses fatos e todos esses dados e mais a percepção que deles esteja tendo a população envolvida. Assim, a realidade concreta se dá a mim na relação dialética entre objetividade e subjetividade (FREIRE,1983, p.35).

Freire levanta questões pertinentes para o pesquisador refletir sobre o seu papel enquanto cientista social ao se deparar com a realidade de uma comunidade, pois a partir do momento em que as incubadoras se propõem a fazer um trabalho de incubação com grupos populares é necessário ter em mente que se trata de uma educação política com um objetivo de transformar a realidade dessas pessoas por meio do trabalho coletivo a fim de produzir e comercializar produtos locais que possibilite geração de renda para a comunidade, Lima (2014) diz que com essa prática tende ao desenvolvimento local por meio da organização política da comunidade com o intermédio da incubadora, uma vez que feita a escolha por valorizar os produtos locais, isso permite um ciclo dentro da comunidade.

[...] economia popular e solidária como uma estratégia para o desenvolvimento local solidário no município de Feira de Santana Bahia, a partir do envolvimento da Incubadora de Empreendimentos Populares Solidários da Universidade Estadual de Feira de Santana (UEFS) como programa capaz de construir conhecimentos e proporcionar formação técnico-científica e cidadã comprometida com os preceitos da economia popular e solidária comuns à promoção do desenvolvimento local solidário (LIMA, 2014, p.22).

Essa interligação entre a incubadora - comunidade permite uma aproximação da realidade concreta como salienta Freire (1983), porém é necessário ter cuidado com a relativização da realidade, pois trata-se de um estudo de caso na esfera micro, isto é, de uma representação da realidade o que não pode ser tomado como realidade absoluta uma vez cada iniciativa tem as suas especificidades e identidades próprias o que corrobora com a metodologia da pesquisaação.

Quando se trata de pesquisa-ação voltada para os problemas da coletividade, como por exemplo, a organização do trabalho em mutirão, o acesso à escola ou à moradia, os objetivos práticos consistem em fazer um levantamento da situação, formular reivindicações e ações. São objetivos práticos voltados para se encontrar uma "saída" dentro do contexto. As soluções imediatas são selecionadas em função de diferentes critérios correspondentes a uma definição dos interesses da coletividade (THIOLLENT, 1947, p.20).

Por isso, quando se escolhe por generalizar a pesquisa o autor corre o risco de esconder características particulares de cada grupo ou comunidade, por exemplo, ao se estudar uma iniciativa de economia popular e solidária é preciso levar em consideração a composição do grupo, se o mesmo é urbano ou rural, se é composto apenas por mulheres ou homens, pois essas particularidades podem influenciar na dinâmica do trabalho.

Pensando nessas especificidades buscou-se embasamento teórico por meio de levantamento de literatura nos assuntos sobre economia popular e solidária, desenvolvimento local, mulher e mercado de trabalho. Para fornecer fundamento teórico que possibilitasse responder ou não, aos objetivos propostos, para tanto foi realizado estudo de caso no qual foram feitas observações junto aos grupos como também a aplicação de um questionário durante a realização da I Feira de Economia Popular e Solidária da UEFS realizada em março de 2016.

\section{A PARTICIPAÇÃo DAS MULHERES NAS INICIATIVAS DE ECONOMIA POPULAR E SOLIDÁRIA}


Como já foram mencionadas acima, as mulheres é a maioria nas iniciativas de economia popular e solidária que são acompanhas pela Incubadora da UEFS, porém nos dados apontados pelo Sistema Nacional de Informações em Economia Solidária - SENAES (2013) o número de sócios nas iniciativas de economia solidária demonstrou uma predominância maior dos homens $(56,4 \%)$ em relação às mulheres $(43,6 \%)$. Conforme tabela abaixo.

Tabela 1- Quantidade de sócios e distribuição segundo sexo.

\begin{tabular}{lcl}
\hline Sexo & Quantidade & $\%$ \\
\hline Mulheres & 620.258 & 43,6 \\
Homenes & 803.373 & 56,4 \\
Total & 1.423 .631 & 100,0 \\
\hline
\end{tabular}

Os dados mostram que a nível nacional a participação feminina nas iniciativas de economia solidária ainda é menor comparado aos dos homens, porém, estes dados podem mudar a partir de uma análise regional ou local, uma vez que esses números não correspondem com realidade local de Feira de Santana, por isso o pesquisador precisa ter cuidado com as conclusões na pesquisa científica, haja vista que nem sempre o micro representa o macro e virse-versa. Os dados do questionário da Feira de Economia Solidária da UEFS (2016) mostram que 77,5\% das iniciativas que participam da Feira são compostos por mulheres e que 22,5\% por homens, vale ressaltar que estiveram presente na Feira 35 iniciativas e que 27 delas era de Feira de Santana, como podem ser observados no quadro abaixo.

Tabela 2- Quantidade e distribuição segundo sexo.

\begin{tabular}{lcc}
\hline Sexo & Quantidade & $\%$ \\
\hline Mulheres & 31 & 77,5 \\
Homens & 9 & 22,5 \\
Total & 40 & 100,0 \\
\hline
\end{tabular}

Fonte: Questionário da I Feira de Economia popular e Solidária da UEFS, 2016.

Numa análise do ponto de vista local existem mais mulheres trabalhando nas iniciativas de economia popular e solidária, um caminho apontado pela literatura para justificar esses números é que se deva ao fato de que as funções desempenhadas pelas mulheres nas iniciativas são tidas como fazeres doméstico e que não necessita de uma especialização mais qualificada, o demostra, todavia, uma leitura equivocada do ponto de vista da economia popular e solidária como economia política dos setores populares, uma vez essa economia dita como outra economia se propõe a empoderar o trabalhar e valoriza-lo sem caracterizar hierarquia ou diferenciação de importância, como acontece no sistema atual que valoriza a especialização técnica do trabalhador e promove essa coisificação do trabalhador.

Hirata (2002) apresenta uma análise densa sobre a precarização do trabalho assalariado como forma de opressão do masculino sobre o feminino predominante no mundo do trabalho principalmente no sistema capitalista, uma vez que a garantia da remuneração do lucro está segundo a teoria neoclássica na produtividade marginal do trabalho ou seja a mais valia, o que impacta diretamente nos salários já que estes são o preço do trabalho, uma das justificativas para a acumulação do capital é a substituição do trabalho por capital, então o mesmo promove a desvalorização das tarefas que dependem exclusivamente de trabalho humano para que os salários sejam baixos e não afetem os seus lucros. Essas tarefas tidas como inferiores em uma sociedade capitalista patriarcal ficam disponibilizada para as mulheres. 
Não pensemos que podemos estudar a divisão sexual do trabalho e o trabalho das mulheres unicamente nas indústrias de mão - de-obra feminina. Ao contrário partimos do pressuposto de que indústrias como a siderurgia, a petroquímica, a de cimento ou a de vidro são lugares privilegiados de análise da divisão do trabalho de acordo os sexos e das concepções de masculinidade e de feminilidade que são ali efetivadas (HIRATA, 2002, p.204).

Nas observações realizadas nas iniciativas ainda é possível detectar resquícios de divisão sexual do trabalho, isso por que ainda existe a influência exacerbada do patriarcado, o que vai de encontro com os princípios de economia popular e solidária, portanto, fica a pergunta: de que maneira a economia popular e solidária como economia política dos setores populares pode contribuir para horizontalizar essa relação da divisão sexual do trabalho?

Pelas leituras e observações, percebo ainda um silenciamento dessa questão como pauta de discussão da luta das mulheres pela igualdade de gênero tendo como instrumento a economia popular e solidária, esta por sua vez tende a corroborar com a justificativa neoclássica de que o trabalho manual, como por exemplo, cozinhar ou fazer a limpeza seja destinado para as mulheres já que os mesmos não necessitam de uma qualificação, já a função de caixa, por exemplo, fica reservado para o homem que resguarda o dinheiro e requer mais qualificação.

A sociedade patriarcal analisada a partir da ótica de economia solidária que Singer (2002) defende tendo como os princípios a igualdade, a solidariedade e a autogestão não responde a realidade, portanto está faltando uma política voltada para a luta das mulheres.

A economia popular e solidária se propõe de muitas maneiras ser outra economia (LIMA, 2016) o que pressupõe que seja diferente do modelo tradicional, Saffioti (2013) entende a inserção da mulher no mundo do trabalho capitalista como uma dupla desvantagem, a primeira na subvalorizarão das capacidades femininas e o seguindo a inclusão periférica no sistema de produção.

\section{CONSIDERAÇÕES FINAIS}

Diante do exposto acima a economia popular e solidária ainda precisa romper com algumas fronteiras estruturais da sociedade para se tornar de fato outra economia, para tanto é necessário que essa mudança seja endógena o suficiente capaz de mudar a estrutura social e política. Essa transformação pode ser alcançada na perspectiva de desenvolvimento local por intermédio das incubadoras universitárias.

No tocante a análise da participação da mulher nas iniciativas de economia popular e solidária, é possível inferir que essa outra economia apresenta contradições quanto aos princípios de igualdade uma vez que é condescendente com a preservação da divisão sexual do trabalho nas iniciativas, sendo assim, o que pode ser apontado como resposta à pergunta sobre a maioria de participantes nas iniciativas serem de mulheres é que as mesmas se sintam valorizada enquanto classe trabalhadora desempenhando uma função que já é familiar a estas.

Com efeito, essa tomada de consciência pode tender a uma valorização do trabalho, o que contribui para a fragmentação do discurso neoclássico em supervalorização do capital e das tradições locais.

\section{REFERÊNCIA}

FREIRE, Paulo. Criando métodos de pesquisa alternativa: aprendendo a fazê-la melhor através da ação. In: Carlos Rodrigues Brandão. Pesquisa Participante. 3. ed. São Paulo: Brasiliense,1983. p.34-41.

HIRATA, Helena. Nova divisão sexual do trabalho? Um olhar voltado para a empresa e a sociedade. 1. ed. São Paulo: Boitempo,2002.

Incubadora de Iniciativas da Economia Popular e Solidária da Universidade Estadual de Feira de Santana - IEPS/UEFS. Projeto Cantina Solidária. Feira de Santana, BA, 2014. 
LIMA, J.R.O. Economia Popular e Solidária e desenvolvimento local: relação protagonizada pela organicidade das iniciativas. Revista Outra Economia. No 18, v.10, p.3-17- 2016.

LIMA, José Raimundo O. A economia popular e solidária como estratégia para o desenvolvimento local solidário. 2014.306 f. Tese (Doutorado em Educação e Contemporaneidade). Universidade do Estado da Bahia, Salvador.

SAFFIOTI, Heleieth. A mulher na sociedade de classe. 3. ed. São Paulo: Expressão Popular,2013.

SINGER, Paul. Introdução à Economia Solidária. 1. ed. São Paulo: Fundação Perseu Abramo, 2002.

THIOLLENT, Michel. Metodologia da pesquisa-ação. São Paulo: Cortez, 1947.

SENAES. MTE. Sistema Nacional de Informações em Economia Solidária. (2013) Atlas Digital da Economia Solidária: dados do segundo mapeamento nacional de empreendimentos econômicos solidários (EES). 2013. Disponível em: $<$ http://sies.ecosol.org.br/atlas〉. Acesso em: 23 ago. 2016. 
